\title{
Mulheres, seus saberes, fazeres e afazeres: o gênero feminino nos museus da imigração alemã no sul do Brasil
}

\author{
Mujer, su conocimiento, obras y tareas: el género femenino en los museos \\ de la inmigración alemán en su de Brasil
}

\author{
Women, their knowledges, do's and chores: the female gender in the \\ museums of German immigration in southern Brazil
}

\author{
Dr. Daniel Luciano Gevehr ${ }^{1}$ \\ Franciele Berti ${ }^{2}$ \\ Shirlei Alexandra Fetter ${ }^{3}$ \\ Vanuza Alves Mittanck ${ }^{4}$
}

\begin{abstract}
Resumo
A pesquisa discute as narrativas visuais produzidas sobre as mulheres de origem germânica nos museus de imigração da Antiga Colônia Alemã de São Leopoldo (RS - Brasil). A constituição das expografias apresentam discursos sobre a mulher de origem germânica - e que através das narrativas expostas nos museus - permitem compreender os imaginários sociais e as representações construídas sobre as mulheres. Valemo-nos da análise das narrativas visuais presentes nas ambiências dos museus, onde encontramos espaços como a "cozinha", a "sala-de-estar", o "quarto" e objetos que procuram colocar em relevo seus saberes e afazeres. Pretendemos mostrar como estes lugares de memória contribuem para a difusão de representações sobre o gênero feminino. Através da investigação pretendemos discutir os elementos simbólicos que buscam materializar, através de sua expografia, uma determinada história das mulheres. Essa, por sua vez, nos revela escolhas e enquadramentos da memória ao mesmo tempo em que define aquilo que deve ser mostrado e guardado para a exposição pública. Os museus são compreendidos na pesquisa como manifestações simbólicas, que falam de forma direta sobre o lugar e sobre os grupos sociais responsáveis pela sua produção, num processo de lutas simbólicas, no qual a imposição de representações sobre o passado passa pela seleção daquilo que deve ser preservado nos espaços sociais, e que passam a representar parte do passado.
\end{abstract}

Palavras-Chave: Mulheres de origem germânica; Narrativas visuais; Museus de imigração.

\section{Resumen}

\footnotetext{
1 (Doutor em História; PPG em Desenvolvimento Regional; Taquara, Rio Grande do Sul, Brasil; danielgevehr@faccat.br). Trabalho apresentado no I Seminário Latino-Americano de Estudos em Cultura SEMLACult, Foz do Iguaçu/PR, Brasil, 2017.

2 (Mestranda em Desenvolvimento Regional (Bolsista Capes); Graduada em Tecnologia de Eventos; PPG em Desenvolvimento Regional; Taquara, Rio Grande do Sul, Brasil; francieleberti@hotmail.com). Trabalho apresentado no I Seminário Latino-Americano de Estudos em Cultura - SEMLACult, Foz do Iguaçu/PR, Brasil, 2017.

3 (Mestranda em Desenvolvimento Regional (Bolsista Capes); Graduada em Pedagogia; PPG em Desenvolvimento Regional; Taquara, Rio Grande do Sul, Brasil; shirleiaf@aluno.faccat.br). Trabalho apresentado no I Seminário Latino-Americano de Estudos em Cultura - SEMLACult, Foz do Iguaçu/PR, Brasil, 2017.

${ }^{4}$ (Mestranda em Desenvolvimento Regional (Bolsista Capes); Graduada em História; PPG em Desenvolvimento Regional; Taquara, Rio Grande do Sul, Brasil; vanuzamittanck@yahoo.com.br). Trabalho apresentado no I Seminário Latino-Americano de Estudos em Cultura - SEMLACult, Foz do Iguaçu/PR, Brasil, 2017.
} 
La investigación analiza las narrativas visuales producidos en las mujeres de origen germánico en los viejos museos de colonias alemanas de inmigración en São Leopoldo (RS - Brasil). La constitución de expografias discursos presentes en la mujer de origen alemán - ya través de las narrativas que se exhiben en museos - nos permiten comprender la social imaginaria y representaciones construido sobre las mujeres. Hemos utilizado el análisis de las narrativas visuales presentes en el ambiente del museo, donde encontramos espacios como la "cocina", el "estar-ser", la "sala" y los objetos que tratan de poner en relieve sus conocimientos y quehaceres. Se pretende mostrar cómo estos lugares de memoria contribuyen a la difusión de las representaciones del género femenino. A través de la investigación tenemos la intención de discutir los elementos simbólicos que buscan materializar, a través de su expografía, una cierta historia de las mujeres. Esto, a su vez, revela las opciones y los marcos de memoria mientras la definición de lo que debe ser mostrado y se almacena para su exhibición pública. Los museos están incluidos en la encuesta como expresiones simbólicas, que hablan directamente sobre el lugar y sobre los grupos sociales responsables de su producción, en un proceso de luchas simbólicas en las que la imposición de las representaciones del pasado implica la selección de lo que debería ser conservada en los espacios sociales, que representarán parte del pasado.

Palabras claves: Las mujeres de origen germânica; narrativas visuales; Museos de inmigración.

\begin{abstract}
The research discusses the visual narratives produced on women of German origin in the immigration museums of the Ancient German Colony of São Leopoldo (RS - Brazil). The constitution of the expógraphies present discourses on the woman of Germanic origin - and that through the narratives exposed in the museums - allow to understand the social imaginaries and the representations built on the women. We analyze the visual narratives present in the ambiences of museums, where we find spaces such as "kitchen", the

"Living room", the "room" and objects that seek to highlight their knowledge and tasks. We intend to show how these places of memory contribute to the diffusion of representations about the feminine gender. Through the investigation we intend to discuss the symbolic elements that seek to materialize, through its expography, a certain history of women. This, in turn, reveals choices and frames of memory while defining what should be shown and saved for public exposure. Museums are understood in research as symbolic manifestations, which speak directly about the place and the social groups responsible for their production, in a process of symbolic struggles, in which the imposition of representations on the past passes through the selection of what must be Preserved in social spaces, and that they represent part of the past.
\end{abstract}

Keywords: Women of Germanic origin; Visual narratives; Immigration Museums.

\title{
1. Introdução
}

A pesquisa investiga os museus de história da imigração alemã no Vale dos Sinos (RS) a partir das narrativas produzidas - através de sua expografia - e difundidas nesses espaços públicos de visitação. Nesse caso, atentamos especialmente para o processo que envolve a produção das narrativas visuais (BURKE, 2004) sobre as mulheres - compreendendo que cada imagem busca contar uma história sobre elas a partir de seu contexto de produção presentes nesses espaços museológicos que por sua vez, difundem representações sobre a mulher na história da imigração alemã, a partir de recortes e seleções, presentes em seus acervos.

Privilegiamos a leitura crítica dos museus (POULOT, 2013), buscando compreender os diferentes mecanismos utilizados na criação das diferentes ambiências (MENESES, 2013), bem como a criação de imagens e representações que procuram retratar uma determinada história sobre as mulheres imigrantes, que chegaram à região a partir de 1824. Nesse sentido, 
a análise crítica que propomos, se baseia na discussão sobre os elementos simbólicos presentes nesses lugares de memória da imigração, relacionando-os com os conceitos de representação, de patrimônio cultural e de identidade étnica e de gênero.

A relação existente entre esses elementos norteia a pesquisa sobre os museus. Ressaltamos que a pesquisa aqui apresentada tem como recorte espacial dois museus localizados nos municípios de Nova Hartz e Sapiranga, ambos de origem germânica na região do Vale dos Sinos (RS). A seleção desses espaços se justifica, uma vez que ambos representam parte do acervo que busca representar a presença da imigração alemã na região e que dessa forma, guardam elementos simbólicos que carregam e perpetuam uma determinada memória do grupo étnico.

A preocupação com a exaltação e a afirmação dos elementos culturais associados à identidade étnica germânica é discutida na pesquisa, na medida em que esses traços identitários se tornam evidentes nas representações construídas e difundidas nos museus, seja através da (re)criação de cenários ou até mesmo através de coleções de diferentes tipos presentes nas exposições permanentes.

A pesquisa pretende ainda discutir, em que medida, esses museus da imigração alemã contribuem para a (re)produção da memória (LE GOFF, 2003) das mulheres na imigração alemã, uma vez que esses museus são compreendidos como lugares de perpetuação e ressignificação da memória e, também, de afirmação de identidades das comunidades locais (municipais) diretamente ligadas à esses espaços museológicos.

Através da investigação realizada nesses lugares de memória, pretendemos discutir os elementos simbólicos presentes, que buscam materializar, através de sua expografia, uma determinada história das mulheres. Essa, por sua vez, nos revela escolhas e enquadramentos da memória (POLLACK, 1989), ao mesmo tempo em que define aquilo que deve ser mostrado e guardado para a exposição pública.

Partimos nossa investigação sobre as representações sobre as mulheres nos museus de imigração alemã da noção de que as produções simbólicas - que em nosso caso estão presentes nos espaços museológicos - devem suas propriedades mais específicas às condições sociais em que são produzidas (BOURDIEU, 2001).

Nesse caso específico, os museus são compreendidos na pesquisa como manifestações simbólicas, que falam de forma direta sobre o lugar e sobre os grupos sociais responsáveis pela sua produção, num processo de lutas simbólicas (CHARTIER, 2002), no qual a imposição de determinadas representações sobre o passado (BOURDIEU, 2001) sofrem - 
necessariamente $-a$ seleção daquilo que deve ser preservado e representado nos espaços sociais, e que passam a representar parte do passado.

É bastante válido o fato de que as representações sociais (JODELET, 2001) expressam sentimentos e ideologias presentes nos grupos que as forjam e definem ainda os objetos eleitos para representa-los. Por sua vez, estas definições partilhadas - e que nesse caso se materializam nos espaços museológicos das suas comunidades - constroem uma visão pretensamente consensual da realidade.

Buscando realizar uma leitura crítica desses espaços, atentamos ainda para Chartier (2002), que se refere às inúmeras possibilidades de leitura de um símbolo, afirmando que este nunca é "lido" de uma única maneira. Segundo Chartier, existem diferentes formas de interpretação de um símbolo, sendo que sua leitura está diretamente vinculada ao contexto no qual o observador está inserido, bem como ao olhar que este lança sobre o objeto em questão.

Compreendemos os museus de imigração como lugares de memória, na acepção de Pierre Nora (1993, p.21), para quem "são lugares, com efeito, nos três sentidos da palavra, material, simbólico e funcional, simultaneamente, somente em graus diversos." Para Nora, a "memória pendura-se em lugares como a história em acontecimentos" (Ibidem, p.25), logo os lugares de memória - como são os museus de imigração alemã - além de serem socialmente construídos, consistem-se em mecanismos de perpetuação da memória (HALBWACHS, 2004).

Halbwachs (2004) mostra-nos como os lugares desempenham um papel fundamental na construção da memória coletiva. Para ele, os lugares que percorremos nos fazem lembrar de fatos ocorridos no passado e, assim, contribuem para a construção da memória, evocando o passado. Quando uma comunidade elege seus lugares de memória, como a construção de um museu e a seleção das peças que o compõe, com forte presença de elementos étnicos - que passam a representá-la - pode-se perceber os condicionantes que estão envolvidos.

Já para Pollack (1989), os lugares de memória somente se constituem em espaço de preservação de uma memória se assim a comunidade os reconhece. Soma-se a isso a constatação de que, no caso dos museus de imigração, a criação desses lugares se associa diretamente ao período em que essas comunidades passam por transformações, como a chegada de migrantes de outras regiões do Rio Grande do Sul e o fenômeno da industrailização, impulsionado na região a partir da década de 1970.

Esses museus constituíram-se enquanto espaços de salvaguarda de uma memória imigrante que não se queria "perder no tempo." Nessa relação de forças, o imaginário (BACZKO: s/d) tem como um de seus pontos de referência - e de lembrança - os lugares de 
memória, na expressão de Nora, para quem "a memória pendura-se em lugares assim como a história em acontecimentos" (1993, p.25).

Já sobre a questão que envolve a lembrança, Le Goff (2003, p.419) aponta para o fato de que a memória requer um exercício constante de atualização - processo que envolve diretamente a criação e manipulação dos espaços e dos objetos que constituem os museus da imigração na região. As exposições nesses lugares de memória contribuem para a manutenção e atualização de uma memória sobre o próprio grupo que a produziu e a preserva.

Atentamos ainda para a relação existente entre esses conceitos - que fundamentam nossa compreensão sobre os museus de imigração - e as discussões sobre identidade, comprrendida nesse estudo como "uma construção social, de certa maneira sempre acontecendo no quadro de uma relação dialógica com o Outro" (CANDAU, 2012, p.09). Para o antropólogo a memória - elemento indispensável da construção da identidade de uma comunidade - é "uma construção continuamente atualizada do passado, mais do que uma construção fiel do mesmo" (Ibidem, p.09).

Assim, a criação e organização de um museu de história, são entendidas como um fenômeno social, no qual o passado da comunidade é redefinido, de acordo com os interesses do presente, que nesse caso, nos parece estar diretamente associado à preocupação com a preservação dos traços identitários, que nesse caso, nos remetem a pensar nas questões da etnicidade - elemento que aparece como traço identitário fundamental nos museus dessas comunidades.

Os museus - vale lembrar - através de suas narrativas, reafirmam os papéis sociais atribuídos às mulheres, no contexto da imigração. Procuram evidenciar "as profissões de mulheres" e que eram consideradas como "boas para um mulher" (PERROT, 2005, p.251). Como também nos ensina PERROT (2005, p.257) "há, de fato, as próprias mulheres, suas aspirações e suas representações, particularmente difíceis de conhecer, pois o discurso ideológico recobre palavras, formata seu ser social e até mesmo suas memórias”. Estes alementos nos fazem refletir criticamente sobre a expografia presente nos museus e sobre os papéis "desenhados" para as mulheres de origem alemã.

Pensando na recriação dos lugares de memória, associados diretamente às funções femininas, a autora lembra que "Era na cozinha que minha avó [...] se sentia totalmente à vontade, dona da casa e das coisas" (PERROT, 2011, p.131). Diz ainda que "O quarto seria por excelência o lugar das mulheres, seu tabernáculo. Tudo concorre para encerrá-las aí: a religião, a ordem doméstica, a moral, a decência, o pudor, mas também o imaginário erótico [...] (Ibidem, p. 131). 
Neste contexto, etnia e gênero assumem uma dimensão de destaque, na medida em que os papéis - socialmente construídos e atribuídos às mulheres de origem alemã - são trabalhados e manipulados de tal forma, que as embiências materializam formas de pensar e representar as mulheres da zona de imigração alemã, que passam a ser patrimonializadas, no espaço museológico.

Percebemos, ainda, que o patrimônio - e em nosso caso mais particular, o museu funciona como um "aparelho ideológico da memória" (CANDAU, 2012, p.158). Isso se explica em virtude do patrimônio da comunidade ser compreendido como um verdadeiro transmissor da memória do grupo, agregando valores, ideologias e formas de pensar, além é claro, de representar o passado dessa comunidade, que agora se encontra patrimonializado através das exposições produzidas nos museus.

Sobre essa questão que envolve o patrimônio e sua produção, Candau afirma ainda que “a história do patrimônio é a história da construção do sentido de identidade e, mais particularmente, aquela dos imaginários de autenticidade que inspiram as políticas patrimoniais" (Ibidem, p.159). A lembrança dos tempos da Colônia e dos primeiros imigrantes alemães parece servir, nesse contexto, de suporte da memória, para se mostrar o quanto se prosperou e o quanto as comunidades de origem germânica prosperaram. Nelas, o trabalho da mulher ganha visibilidade.

Buscando melhor fundamentar nossa análise, buscamos discutir os sistemas classificatórios que envolvem a produção dessas identidades, que em nosso caso apontam para necessidade de reafirmação da germanidade - compreendida como uma categoria que remete a identidade étnica compartilhada pela comunidade, que os remete a "lembrar e perpetuar" o passado imigrante. Sobre essa questão Giralda Seyferth (2011) se refere ao Deutschtum, que para ela expressa a germanidade, que seria uma espécie de laço identitário, que une os imigrantes e seus descendentes através da etnicidade.

Woodward nos ajuda a entender essa questão, afirmando que as identidades são fabricadas através de um processo que envolve a marcação das diferenças (2014), que segundo ela ocorre através de sistemas simbólicos de representação. Segundo a autora, a identidade depende diretamente da diferença, na medida em que, a diferença simbólica ou social, se estabelece por meio de sistemas classificatórios, onde se definem aquilo que é nosso ou dos outros, ou entre aquilo que queremos mostrar e aquilo que queremos esconder.

É fundamental considerar os espaços museológicos enquanto um elemento de grande importância para a o Patrimônio Cultural da imigração alemã no sul do Brasil. A criação e atualização desses espaços - portadores de uma historicidade particular e inseridos, cada um 
deles, no contexto de produção de suas comunidades - pode ser compreendido como uma necesssidade do próprio grupo, responsável por sua criação, na medida em que esse mesmo grupo procura "se fazer" representar nesses lugares de memória.

Nessa perspectiva, podemos conceituar o Patrimônio Cultural como um conjunto de bens de natureza material e imaterial que, por sua vez, são considerados coletivos e preservados durante o tempo (MAIA, 2003). Há de se considerar também que o Patrimônio cultural comporta, ainda, os diferentes costumes de viver de um povo, transmitidos de geração a geração e recebidos por tradição. Esses, para se tornarem um Patrimônio, precisam ser reconhecidos e compartilhados pela comunidade que os produzem - fenômeno que se torna evidente no processo de criação e eleição daquilo que irá constituir os museus da imigração alemã na região do Vale dos Sinos.

Também Choay (2006, p.11), apresenta uma clara definição sobre o patrimônio, que pode ser compreendido como "um bem destinado ao usufruto de uma comunidade que se ampliou a dimensões planetárias, constituído pela acumulação contínua de uma diversidade de objetos que se congregam por seu passado comum". Podemos considerar o patrimônio cultural como fruto da identidade de uma comunidade. Este representa, em última análise, aquilo que deve ser preservado, ou seja, o que não deve ser esquecido, ainda que, na maioria das vezes, atendendo aos interesses de determinados grupos que o manipula.

O mиseu - compreendido como expressão do patrimônio - engloba, ainda, saberes, lugares e modos de fazer, que comunicam algo sobre a identidade de quem as produz, e que por sua, vez, são transmitidos através das gerações. Decorre daí que os hábitos e as tradições de uma comunidade nos dizem e revelam parte da sua cultura. Ainda, para Veloso (2006), o conceito de referência cultural ressalta o processo de produção e reprodução de um determinado grupo social e aponta para a existência de um universo simbólico compartilhado.

Consideramos fundamental que "a questão da memória, da busca identitária e da apreensão do passado como patrimônio memorialístico apresenta-se como uma rica fronteira entre a História e o Turismo" (MENESES, 2004, p.15). Assim "a construção/invenção do passado como atrativo para quem viaja, parte de interpretações que são instrumentalmente inseridas no método da História, mas, também, por construções de caráter popular, lendário e mitológico" (Ibidem, p.15).

Devemos considerar ainda que, de acordo com Meneses (2004, p.75) o museu é um lugar que toma como base três valores indissociáveis: $\mathrm{O}$ valor identitário, que considera o patrimônio como gerador constante de construção de imagens, significados e identidades; o valor econômico, que toma o patrimônio como gerador de oportunidades econômicas; e o 
valor social, que defende que os projetos interpretativos devem gerar a melhoria da qualidade de vida da comunidade que administra esse patrimônio.

Percebemos que os museus de imigração alemã da região, se articulam diretamente como espaços de potencialidade turística. Esse elemento faz com que os museus compreendidos como parte de seu Patrimônio Cultural - sejam percebidos pelas próprias comunidades como espaços de desenvolvimento local e regional (VARINE, 2013), na medida em que podem atrair visitantes de diversos lugares, contribuindo com isso para a promoção do desenvolvimento econômico dos municípios.

Ao mesmo tempo, esses lugares de memória da comunidade são espaço de preservação de sua identidade e também espaços em potencial para "se mostrar" parte das tradições herdadas dos imigrantes alemães que colonizaram a região e que são, em grande parte, ainda compreendidos como uma espécie de guia das suas ações no presente. Nessa perspectiva, observa-se que as tradições (HOBSBAWN, 2008) herdadas dos imigrantes alemães fazem parte do cotidiano dessas comunidades.

Esses elementos podem ser percebidos na medida em que encontramos uma forte preocupação em manter viva a fala da língua alemã, através do Hunsrik, que é praticado cotidianamente e da preservação de diferentes usos e costumes (THOMPSON, 2013), como as comidas, as músicas, a religiosidade e as festas, deixados pelos alemães que fundaram as comunidades no século XIX.

A preocupação com a manutenção dos elementos étnicos, ligados à herança germânica na região, aparece como um elemento identitário que dá sentido e perpetua, através das gerações, o sentimento de pertencimento ao grupo étnico que deu origem às comunidades.

Os museus, que acabam muitas vezes, espetacularizando (LLOSA, 2013), através de sua expografia, uma narrativa sobre a imigração alemã no sul do Brasil, atuam como difusores de uma representação/imagem sobre esse imigrante, que permite a (re)atualização da memória através da manipulação do imaginário, que por sua vez, contribui de forma decisiva na manutenção dos traços identitários atribuídos aos imigrantes alemães e seus descendentes.

\section{As narrativas visuais nos museus de Nova Hartz e Sapiranga}

Selecionamos para análise dois museus. Decidimos por tal recorte, considerando as especificidades de cada espaço. Partimos da definição proposta por Gonçalves (2009), para quem o museu-narrativa se constitui em um espaço de exposição, inserido em um espaço urbano, mas no qual a relação com o público ainda guarda marcas bastante pessoais. Esse é 
precisamente o caso dos museus de imigração que estamos analisando e nos quais observamos, de forma bastante evidente, uma relação muito próxima entre esses lugares de memória e a comunidade que o produz e o mantém vivo. Nessa relação interpessoal, "por meio da qual se dá o fluxo de trocas entre doadores e diretores de museus" (GONÇALVES, 2009, p.178) é que ocorre a definição daquilo que será exposto e que, constituirá parte do material de expografia presente no museu.

É nesse contexto que iremos acompanhar o processo que o autor denomina como "invenção do patrimônio" (Ibidem, p.179). De acordo com ele essa "invenção" - que consiste na seleção e organização - das exposições do museu, "vem acompanhada de valores, como autonomia e liberdade, assumidos por sujeitos individuais ou coletivos" (Ibidem, p.179). A partir disso é que analisamos dois museus que, apresentam características semelhantes quanto aos seus objetivos e forma de organização e seleção de sua expografia.

O primeiro é o Museu Municipal de Nova Hartz, criado pela Prefeitura Municipal em 1999, e que está localizado na área central do município e ocupa uma antiga residência, localizada na atual praça central da área urbana.

Organizado a partir de diferentes ambientes, que respeitam a divisão original da casa, o museu apresenta um rico acervo, constituído de móveis, objetos e fotografias, que procuram evidenciar a presença dos imigrantes alemães na localidade. Dessa forma, o museu se apresente como um espaço de memória da imigração e tem como tema principal do seu acervo a imigração e a colonização alemã em Nova Hartz.

$\mathrm{Na}$ parte central do museu encontramos objetos que evidenciam o estilo de vida dos primeiros moradores, através dos móveis e utensílios domésticos que eram utilizados desde o século XIX até meados do século XX, quando o desenvolvimento da indústria calçadista no município transformou radicalmente o estilo de vida de seus moradores. Podemos observar como no exemplo na imagem abaixo - a mistura de elementos de diferentes épocas na expografia, que contam a trajetória de transformação da comunidade, através dos objetos.

Notamos na constituição desse ambiente a preocupação em mostrar o ambiente da casa, que é constituído basicamente da cozinha - lugar de preparação dos alimentos, principal espaço social da casa e lugar da mulher, por excelência - no qual as pessoas se reuniam para realizar as mais diferentes atividades e celebrar seus usos e costumes cotidianos, que não se revela apenas através dos móveis e objetos, mas também da produção de bordados, feitos à mão e que contém dizeres, que revelam valores familiares compartilhados. Estes objetos revelam parte dos saberes e afazeres das mulheres, tidos como "coisas de mulheres". 
A associação de diversos elementos culturais aparece na imagem acima, na qual utensílios domésticos - utilizados no cotidiano das mulheres - aparecem em associação com uma cuia de chimarrão - um elemento típico da cultura gaúcha que foi assimilado pelos imigrantes alemães no Rio Grande do Sul - e outros objetos do uso cotidiano da comunidade nos tempos que antecederam a chegada da energia elétrica e a modernização imposta pelo espaço urbano que se organizava a partir da década de 1950 em Nova Hartz.

Neste contexto, o pano de parede bordado à mão pelas mulheres, aparece como um artefato que demonstra o trabalho doméstico desempenhado pelas mulheres, que além das atividades cotidianas, encontravam tempo para bordar e cuidar da ornamentação da casa. Aliás, o cuidado com a limpeza e a organização da casa é um dos aspectos bastante evidenciado através do museu, que procura imprimir a ideia de organização e cuidado com a casa como atividades diretamente ligadas ao gênero feminino. A mulher aparece, portanto, como elemento de destaque em ambientes que revelam suas atividades no espaço privado do lar.

O espaço da cozinha e do quarto, são os espaços de maior visibilidade no museu, uma vez que ocupam a maior parte física e concentram um expressivo conjunto de objetos, que se associam a vida das mulheres. O cuidado com os detalhes destes ambientes evidencia o trabalho desempenhado pelas mulheres, no espaço interno da casa.

Nestes espaços, a mulher é representada como uma espécie de "rainha do lar". Se no espaço público era seu marido quem comandava e tomava a maior parte das decisões, em casa - no lar - era ela, a mulher, a mãe, dona de casa, quem ocupava o lugar de centralidade.

Outro elemento de destaque no museu é a exposição de fotografias e documentos ligados às atividades educacionais, festivas e religiosas da comunidade. $\mathrm{Na}$ imagem apresentada acima, observamos parte da história da comunidade, que se revela aos visitantes através de poses em atos cívicos, em atividades nas escolas e até mesmo na exposição do certificado de Ensino Confirmatório de um membro da Igreja Evangélica de Confissão Luterana (IECLB). Neste espaço, a mulher também é representada através de sua religiosidade.

Este aspecto, de caráter religioso, associado ao luteranismo - que naturalmente coexistia com o catolicismo romano - é um elemento de forte vinculação à etnicidade que constitui a comunidade, visto que a prática religiosa ligada à igreja luterana alemã é um traço identitário que distingue essa comunidade, nas quais a germanidade não se fazia presente. $\mathrm{O}$ museu, a partir de sua organização, procura demonstrar a preocupação dos imigrantes alemães e seus descendentes quanto à preservação dos valores identitários, que têm a família, o 
trabalho e a religiosidade como fundamentos que orientam as condutas e as ações coletivas da comunidade.

O trabalho, representado através dos instrumentos, cuidadosamente organizados na exposição, busca valorizar as atividades desempenhadas na comunidade e que dessa forma dão destaque para a evolução do trabalho ao longo do tempo. Exemplo disso são as ferramentas utilizadas nas atividades agropastoris, que associam o passado desses imigrantes ao espaço rural.

No mesmo ambiente, são apresentadas as novas tecnologias que surgiram ao longo do século XX, como as máquinas de calçado, as balanças e o primeiro computador que chegou ao município, na década de 1980. Neste espaço, o homem é quem ocupa lugar de destaque, estando os "ofícios de mulher" praticamente ausentes.

A mistura de objetos que representam as atividades econômicas desenvolvidas, em diferentes épocas e contextos, pode ser compreendida como uma tentativa de mostrar aos visitantes o progresso alcançado pelos seus moradores. As diferenças evidenciadas entre a chegada dos primeiros imigrantes e o tempo mais recente se apresentam como um forte elemento de valorização da coletividade, que através do trabalho e da preservação da cultura trazida pelos imigrantes alcançaram o desenvolvimento do município.

O segundo lugar de memória que investigamos é o Museu Municipal Adolfo Evaldo Lindenmeyer - que presta homenagem ao ex-vereador da cidade e também descendente de alemães - que está localizado na área central de Sapiranga, no prédio da antiga estação férrea, conhecida como "Estação Sapyranga", desativada em 1964. O museu foi criado pela Prefeitura Municipal em 1996 e tem como tema principal de seu acervo a imigração e a colonização alemã no município.

Os ambientes do museu são constituídos por diferentes temáticas, que se dividem entre a casa do imigrante, a venda colonial e a evolução da economia no município. Além disso, o museu conta com uma pequena exposição de obras que retratam o episódio dos Mucker único movimento messiânico ocorrido no Brasil em ambiente protestante e que foi liderado por uma mulher, Jacobina Mentz Maurer. Neste espaço, a mulher - Jacobina - é quem ganha relevo na história da imigração alemã.

Assim, logo na entrada do museu, nos deparamos com a venda colonial que existiu na localidade, desde o século XIX e funcionava em uma edificação em estilo enxaimel. A venda, cuja imagem podemos observar acima, conta com diferentes objetos, que procuram contar parte da história da comunidade, em especial a economia de trocas de produtos, amplamente conhecida em toda região colonial alemã do Rio Grande do Sul. O espaço da venda representa 
- vale lembrar - parte do universo essencialmente masculino e público, no qual as mulheres praticamente não são representadas.

Já a casa do imigrante é representada pela cozinha e pelo quarto do casal, que mostram parte do mobiliário e dos objetos de uso cotidiano desses imigrantes - retratando a evolução dos objetos ao longo do tempo - constituindo um conjunto de artefatos de diferentes épocas e contextos da história de Sapiranga. Neles as "coisas de mulheres" ganham, mais uma vez relevo, na perspectiva de contar a história das mulheres na zona de imigração alemã.

A mesa da cozinha e o banco onde todos se sentavam para fazer as refeições coletivamente, os utensílios domésticos, os panos de parede com dizeres em alemão - e de grande apelo religioso - e o mobiliário que constituía o quarto do casal são exemplos do patrimônio cultural da comunidade. Esses, por sua vez, remetem os visitantes, a lembrarem do tempo dos imigrantes alemães e de suas dificuldades frente ao novo ambiente da América.

Objetos como formas para confecção de bolachas, doces em compotas, moedor de café e outros vários utensílios do cotidiano são colocados em relevo na exposição da casa, que demonstra também a preocupação com a organização das tarefas e a limpeza com o espaço da casa, que cabia principalmente à mulher.

Percebe-se a vinculação do espaço doméstico da casa a presença da mulher, que além de cuidar da família, de ajudar seu marido nas atividades do campo, cuidava muito bem da casa - como uma forma de representação dos usos e costumes dessa germanidade. A cozinha e o quarto, nesse contexto, reproduzem formas de pensar e sentir as questões de gênero.

Em Sapiranga aparece a preocupação com a representação do trabalho, que é apresentado ao visitante através da exposição que mostra a evolução do trabalho, desde os tempos da Colônia até o apogeu do calçado - elemento de destaque na evolução econômica do município e que se constitui a principal atividade econômica desenvolvida atualmente.

$\mathrm{Na}$ área externa do museu, encontramos uma réplica da estrada de ferro, inaugurada em 1903 e que ligava Sapiranga a Porto Alegre. A presença da estada de ferro é uma compreendida pela comunidade como uma forma de representar o desenvolvimento econômico da localidade no final do século XIX, logo após o desfecho do conflito do Mucker, que encerrou em 1868, com a vitória das forças imperiais sobre o grupo liderado por Jacobina nas imediações do morro Ferrabraz. Os trilhos do trem procuram simbolizar o progresso alcançado pelos alemães.

\section{Conclusões}


Percorrer os caminhos que compõe a produção das narrativas visuais sobre as mulheres nos museus da imigração alemã nos faz pensar sobre a complexidade que envolve a manipulação da memória e sobre os diferentes elementos que estão envolvidos nesse jogo de poder, que procura estabelecer uma representação sobre o passado - em espacial sobre as questões de étnicas e de gênero. A análise desses lugares de memória da imigração no Vale dos Sinos nos permitiu melhor compreender sobre os processos que operam nessa tentativa de registro do passado.

Torna-se clara a intenção, por parte daqueles que produziram esses lugares de memória, de imprimir, através do tempo, uma memória, que faz lembrar a rusticidade desse passado imigrante em suas comunidades, ao mesmo tempo em que acabaram dando certa visibilidade às mulheres, muitas vezes negligenciada pela historiografia considerada tradicional e que exalta apenas o trabalho masculino na zona de imigração.

A lembrança dos tempos difíceis - que marcaram os primórdios da imigração alemã e a valorização de elementos simbólicos, materializados através dos objetos dos museus, ligados à família, ao trabalho, à religiosidade e a busca do ideal de prosperidade, se mostraram evidentes nas narrativas analisadas.

As mulheres desempenharam diferentes papéis, nesse contexto, na medida em que são representadas especialmente no espaço doméstico, ou seja, desempenhando atividades fundamentais para o provento da família, da criação dos filhos, do cuidado com a casa e da exaltação de seus saberes e afazeres. Estes ofícios, considerados como "trabalho de mulheres", ainda que condicionados à questão de gênero, permitem dar certa visibilidade à presença das mulheres na zona de imigração alemã no sul do Brasil, rompendo com décadas de silêncio na história (PERROT, 2005).

Os museus, enquanto lugares que suportam lembranças e difundem imagens são, sem dúvida, um espaço de discussão acerca dos interesses e motivações que levam essas comunidades a buscarem, incessantemente, (re)enquadramentos de suas memórias. Nesses enquadramentos, as mulheres, acabam sendo, inevitavelmente, enquadradas dentro de certos padrões culturais, que as colocam, essencialmente no espaço doméstico do lar, condicionadas ao espaço privado e controladas, na maioria das vezes, pelo poder da dominação masculina.

\section{Referências}

BACZKO, B. Imaginação social. In: Enciclopedia Einaudi (Anthropos-Homem). Portugal: Imprensa nacional/Casa da Moeda, s/d. v.5. p. 309-310. 
BOURDIEU, P. O poder simbólico. 4. ed. Rio de Janeiro: Bertrand. 2001. 313p.

BURKE, P. Testemunha ocular: história e imagem. Bauru: EDUSC, 2004. 270p.

CANDAU, J. Memória e identidade. São Paulo: Contexto, 2012. 219p.

CHARTIER, R. À beira da falésia. A história entre certezas e inquietude. Porto Alegre: UFRGS, 2002. 275p.

CHOAY, F. A Alegoria do Patrimônio. 3 ed. São Paulo: Unesp, 2006. 282p.

GONÇALVES, J. Os museus e a cidade. In: ABREU, R.; CHAGAS, M. (org). Memória e Patrimônio. Ensaios Contemporâneos. 2 ed. Rio de Janeiro: Lamparina, 2009. p. 171-186.

HALBWACHS, M. A memória coletiva. São Paulo: Centauro, 2004. 224p.

HOBSBAWN, E. Introdução: a invenção das tradições. In: HOBSBAWN, Eric \& RANGER, Terence. A Invenção das Tradições. 5 ed. São Paulo: Paz e Terra, 2008. p. 09-23.

JODELET, D. Representações sociais: um domínio em expansão. In: JODELET, Denise (org.). As representações sociais. Rio de Janeiro: EDUERJ, 2001. p.17-44.

Le GOFF, J. História e memória. 5. ed. Campinas: UNICAMP, 2003. 504p.

LLOSA, M. V. A civilização do espetáculo. Uma radiografia do nosso tempo e da nossa cultura. Rio de Janeiro: Objetiva, 2013. 207p.

MENESES, U. T. B. de. A Exposição museológica e o conhecimento histórico. In: FIGUEIREDO, B. G.; VIDAL, D. G. Museus. Dos Gabinetes de Curiosidades à Museologia Moderna. 2 ed. Belo Horizonte: Fino Traço, 2013. p.15-88.

MENESES, J. N. C. História e Turismo Cultural. Belo Horizonte: Autêntica, 2004. 127p.

NORA, P. Entre memória e história. A problemática dos lugares. Projeto história. São Paulo, n. 10, p.07-28, dez. 1993. [Revista do Programa de Estudos Pós-graduados em História e do Departamento de História PUCSP].

PERROT, Michelle. As mulheres ou os silêncios da história. Bauru. São Paulo: EDUSC, 2005. 503p.

PERROT, Michelle. A história dos quartos. São Paulo: Paz e Terra, 2011. 344p.

POLLACK, M. Memória, esquecimento, silêncio. Estudos Históricos, Rio de Janeiro, v. 2, n. 3, p.03-15, 1989.

POULOT, D. Museu e Museologia. Belo Horizonte: Autêntica, 2013. 159p.

POUTIGNAT, P; STREITFF-FENART, J. Teorias da Etnicidade seguido de Grupos Étnicos e suas Fronteiras de Frederik Barth. São Paulo: Editora da UNESP, 1998. 
SEYFERTH, G. A dimensão cultural da imigração. Revista Brasileira de Ciências Sociais. Vol. 26, n. 77. p. 47-62, 2011.

THOMPSON, E. P. Costumes em comum. Estudos sobre cultura popular e tradicional. São Paulo: Cia. Das Letras, 2013. 493p.

VARINE, H. de. As raízes do futuro. O patrimônio a serviço do desenvolvimento local. Porto Alegre: Medianiz, 2013. 256p.

VELOSO, M. O Fetiche do Patrimônio. Habitus. Goiânia, v.4, n.1, p.437-454, jan-jun. 2006.

WOODWAR, K. Identidade e diferença: uma introdução teórica e conceitual. In: SILVA, T. T. da (org). Identidade e diferença: a perspectiva dos Estudos Culturais. 14 ed. Petrópolis: Vozes, 2014. p. 07-72. 